\title{
Superficial siderosis of the central nervous system with epilepsy originating from traumatic cervical injury: illustrative case
}

\author{
Liqing Xu, BD, Changwei Yuan, BD, Yingjin Wang, BD, Shengli Shen, MD, and Hongzhou Duan, MD, PhD \\ Department of Neurosurgery, Peking University First Hospital, Xicheng District, Beijing, China
}

\begin{abstract}
BACKGROUND Superficial siderosis of the central nervous system (SSCNS) is a rare condition that results from hemosiderin deposition in the brain, brainstem, cerebellum, and spinal cord as a result of chronic, repeated, and recurrent subarachnoid hemorrhage. SSCNS that originates in the spinal cord is rarely reported, and epilepsy as a manifestation of such a case has not been reported before.

OBSERVATIONS The authors reported a rare case of SSCNS with epilepsy originating from traumatic cervical injury and presented a literature review of all reported SSCNS cases that originated in the spine. The patient was a 29-year-old man with a 16-year history of progressive headache accompanied by seizures, ataxia, and sensorineural hearing loss. He had experienced a traumatic cervical injury at age 7 . Magnetic resonance imaging revealed a characteristic hypointense rim around the pons and cervical spinal cord on susceptibility-weighted imaging scans. Cerebrospinal fluid examination during a headache episode confirmed subarachnoid hemorrhage and increased intracranial pressure. Surgical exploration revealed a $\mathrm{C} 6$ dural defect with bone spurs inserted into the dura mater. After the patient underwent dura mater repair and shunt implantation, his symptoms disappeared completely except for hearing loss.
\end{abstract}

LESSONS This rare case indicated that symptomatic epilepsy followed by SSCNS can be eliminated by complete repair of the cervical dura mater.

https://thejns.org/doi/abs/10.3171/CASE2114

KEYWORDS superficial siderosis; epilepsy; trauma; spine

Superficial siderosis of the central nervous system (SSCNS) is an uncommon and unrecognized disorder characterized by hemosiderin deposition on the surface of the brain, brainstem, cerebellum, and spinal cord as the result of chronic or intermittent bleeding into the subarachnoid space, which causes irreversible damage to the CNS and results in a series of neurological manifestations. ${ }^{1,2}$ The typical triad of SSCNS symptoms includes progressive cerebellar ataxia, central motor disability, and sensorineural hearing loss. ${ }^{3}$ Other symptoms, such as chronic increased intracranial pressure (ICP) and hydrocephalus, develop in approximately one-third of patients because of obstruction of the ventricular foramina and/or malabsorption of cerebrospinal fluid (CSF). ${ }^{4}$ Epilepsy is a rare manifestation of SSCNS as discussed in the literature, although patients with SSCNS may have a prior history of head trauma or surgical procedures. ${ }^{5,6}$ Most reported cases of SSCNS originate from traumatic brain injury and intracranial hemorrhage or surgery; relatively few cases originate from spinal injury, and in this latter group, epilepsy has not been reported. ${ }^{7}$ Medical or surgical treatments for SSCNS are often ineffective, and most reported cases progress slowly and inexorably. Although treatment with deferiprone ${ }^{8}$ and cochlear implants ${ }^{9}$ have been tried, successful therapy still depends on determining the etiology of chronic bleeding and precise treatment. We report an interesting case of SSCNS originating from a traumatic cervical injury. The patient experienced intractable epilepsy and increased ICP in addition to the typical triad. His condition was treated successfully with repair of the dura mater.

\section{Illustrative Case}

A 29-year-old male patient presented with a 16-year history of progressive headache accompanied by intractable seizures and sensorineural hearing loss. The headache consisted of sudden-onset frontal or occipital radiating pain that was often accompanied by photophobia, diplopia, nausea, and vomiting. The pain was aggravated when he lay flat, and it gradually increased in severity and frequency. In the previous year, every headache was accompanied by generalized

ABBREVIATIONS CSF = cerebrospinal fluid; $C T=$ computed tomography; $I C P=$ intracranial pressure; MRI = magnetic resonance imaging; SSCNS = superficial siderosis of the central nervous system.

INCLUDE WHEN CITING Published April 12, 2021; DOI: 10.3171/CASE2114.

SUBMITTED January 6, 2021. ACCEPTED January 25, 2021.

(c) 2021 The authors, CC BY-NC-ND 4.0 (http://creativecommons.org/licenses/by-nc-nd/4.0/). 


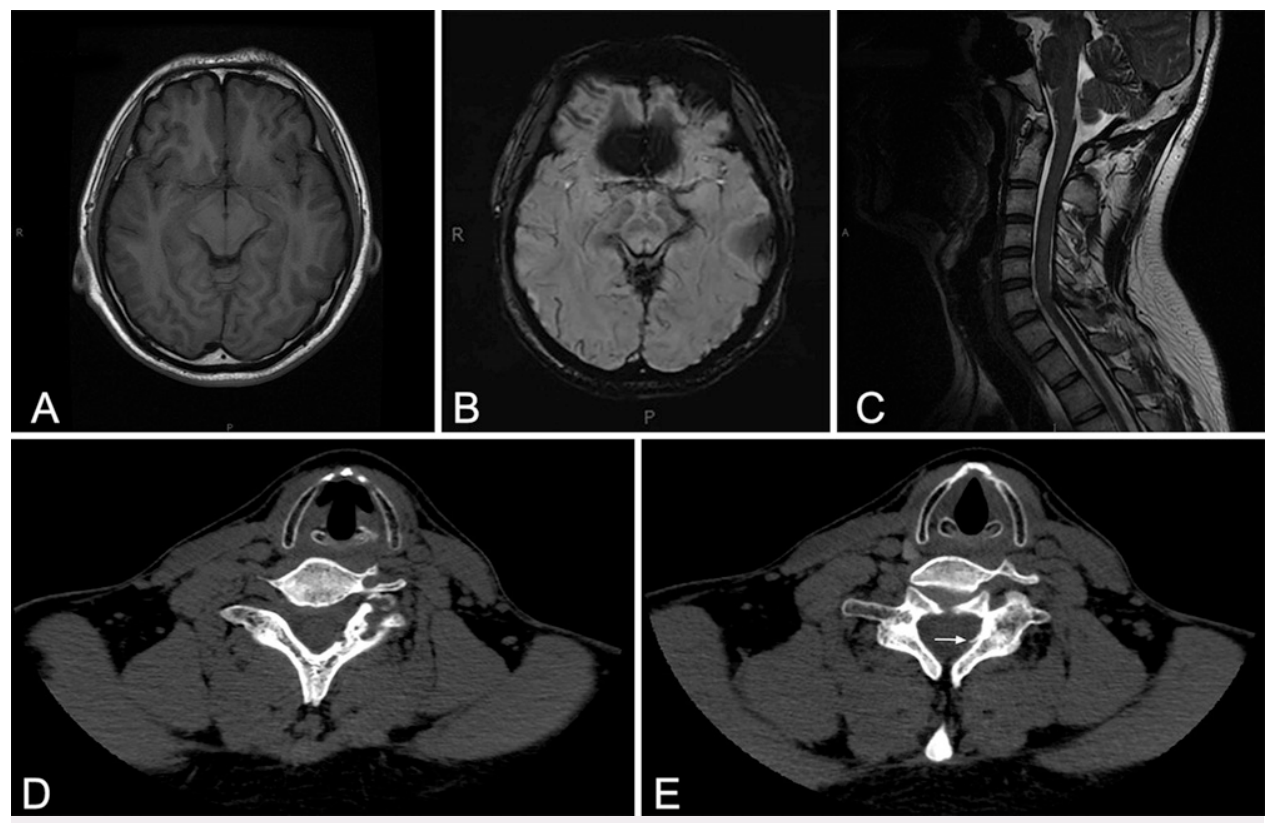

FIG. 1. A and B: Axial T2-weighted and susceptibility-weighted brain MRI shows the characteristic hypointense rim along the dorsolateral pons. C: Sagittal T2-weighted cervical spine MRI shows a hypointense lesion in the C6-7 subdural and epidural space, indicating previous hemorrhage. D and E: CT of the cervical spine shows hyperosteogeny of the left $\mathrm{C} 7$ lamina, with a bone spur protruding into the spinal canal (arrow).

tonic-clonic seizures, which fully subsided several minutes later. Although various antiepileptic drugs were used, the seizures were not controlled effectively. The patient also developed progressive deafness and ataxia within the previous 5 years, and the hearing loss was obvious on the left side. When he was referred to our hospital, epilepsy with headache onset was occurring approximately twice a month; furthermore, the patient was unable to walk independently, and the hearing loss in the left ear was almost complete.

When he was 7 years old, the patient had experienced a fall that resulted in a short period of disturbance in consciousness and neck pain. Neurological examination upon admission to the hospital revealed a deterioration of memory, decreased visual acuity without papilledema, nystagmus, hearing loss, positive Rinne test result, and ataxic gait. Other cranial nerve and sensory examinations produced normal results. On brain magnetic resonance imaging (MRI), axial T2weighted images (Fig. 1A) and susceptibility-weighted imaging scans (Fig. 1B) showed a characteristic rim of hypointensity along the dorsolateral pons, which indicated the deposition of hemosiderin. CSF examination at headache onset indicated a high ICP $\left(29 \mathrm{~cm} \mathrm{H}_{2} \mathrm{O}\right)$ and blood (>1,000 red blood cells per $\mathrm{mm}^{3}$ ), suggesting subarachnoid hemorrhage. Except for a slight increase in protein concentration, no specific positive results were shown in biochemical or immunoelectrophoresis examinations of CSF. No abnormalities were present on routine electroencephalography except for a wide slow wave throughout the brain. To determine the reason for the subarachnoid hemorrhage, digital subtraction angiography of the brain and spinal cord was performed; however, neither aneurysms nor arteriovenous malformations were found. Based on the prior history of falling, further MRI of the cervical spine was performed, which revealed a hypointense lesion in the subdural and epidural space of C6-7 on sagittal T2weighted images (Fig. 1C). This finding indicated the possibility of a previous hemorrhage. Cervical computed tomography (CT) examination revealed hyperosteogeny of the left C7 lamina (Fig. 1D) with a bone spur protruding into the spinal canal (Fig. 1E), which indicated a previous fracture. Because the osteophyte was believed to be the cause of recurrent subarachnoid hemorrhage, surgical exploration was indicated.

During the operation, we found a wide deposition of hemosiderin around the spinal cord, and a protruding osteophyte (Fig. 2) pierced the dura and the subdural space of the spinal cord, leading to an apparent dural defect. The osteophyte was removed, and the subcutaneous fascia was sutured over the dural defect in a watertight fashion. The patient recovered well after the operation; however, he experienced

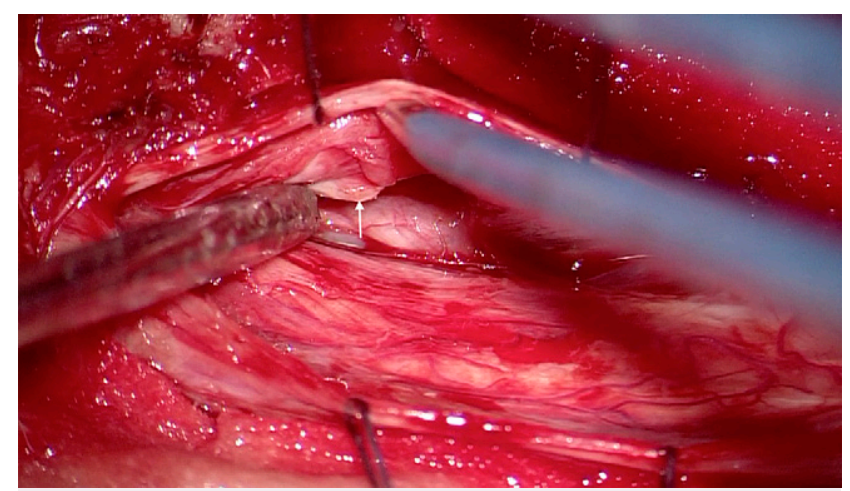

FIG. 2. Intraoperative photograph shows deposition of hemosiderin on the surface of the spine and a bone spur (arrow) protruding into the subdural space, leading to a dural defect in the left posterior part of the cervical spine. 


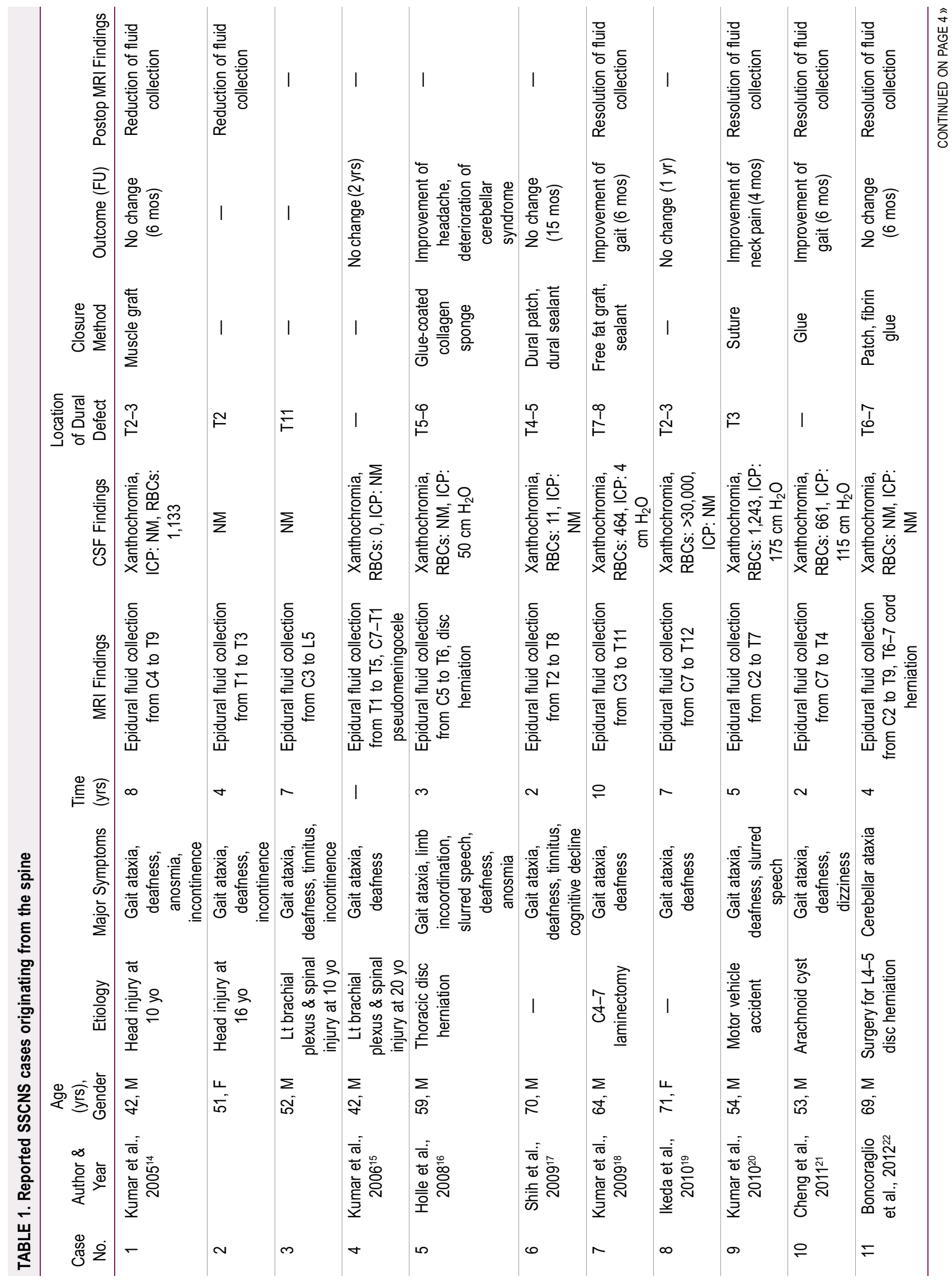




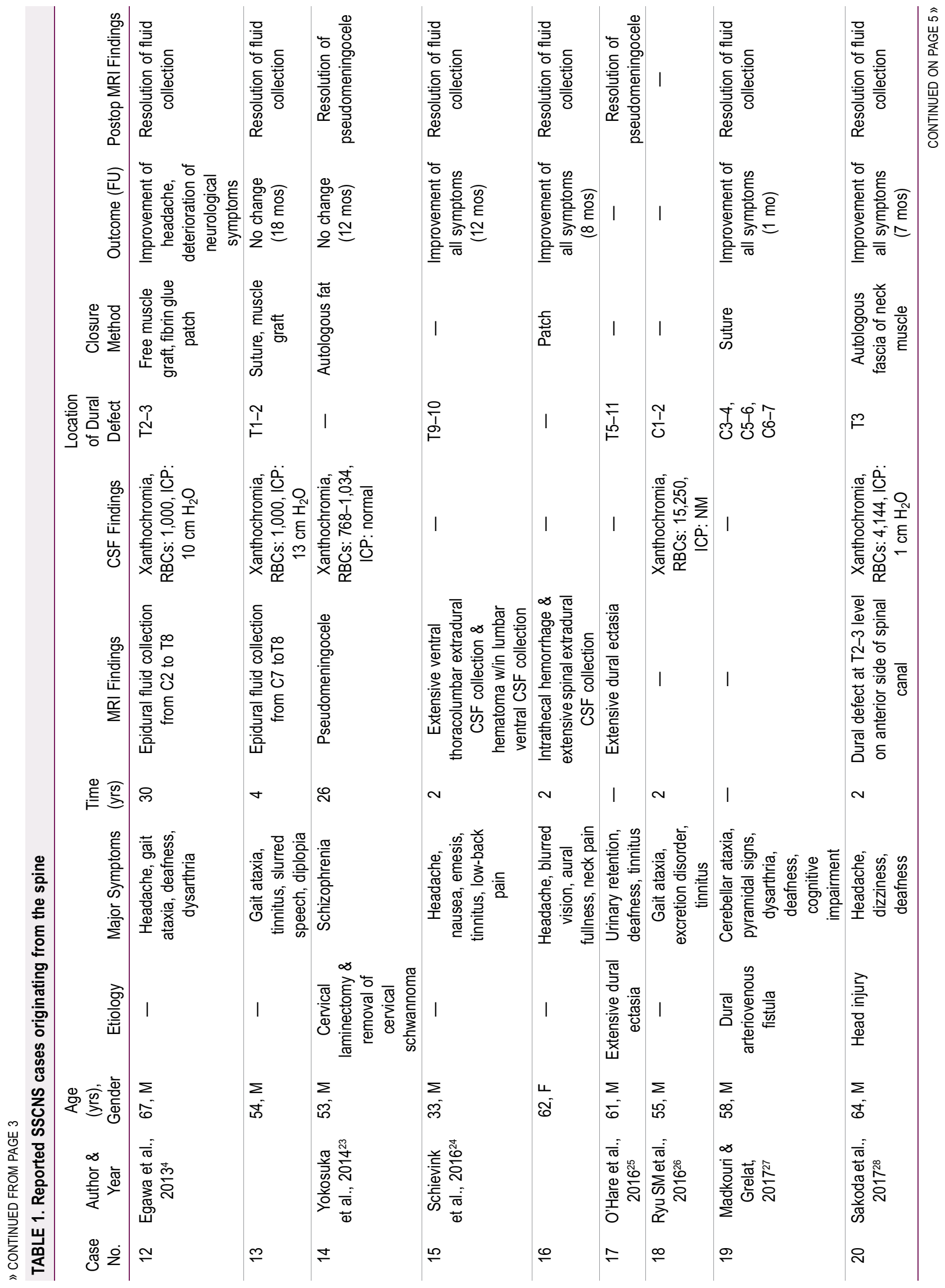




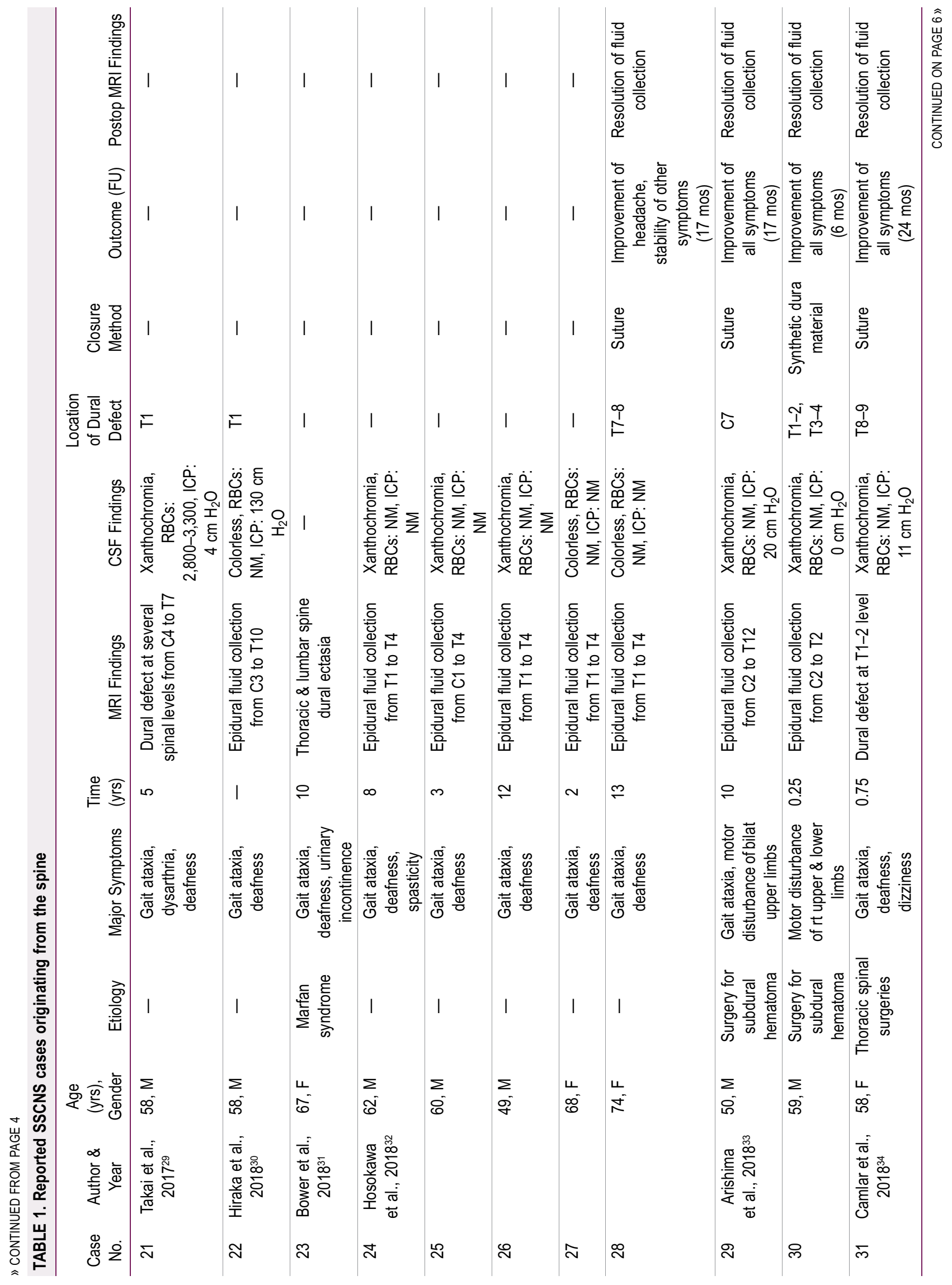




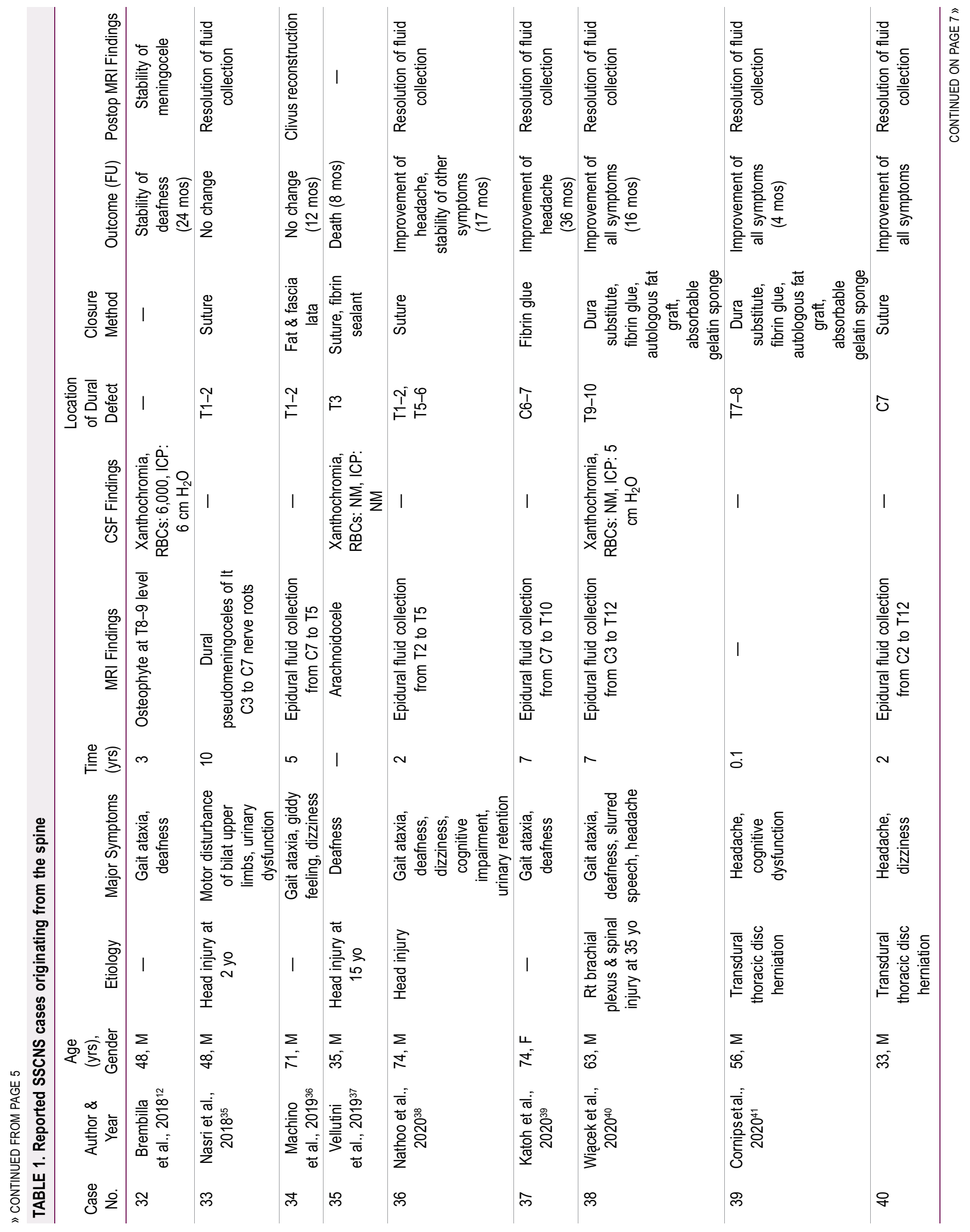




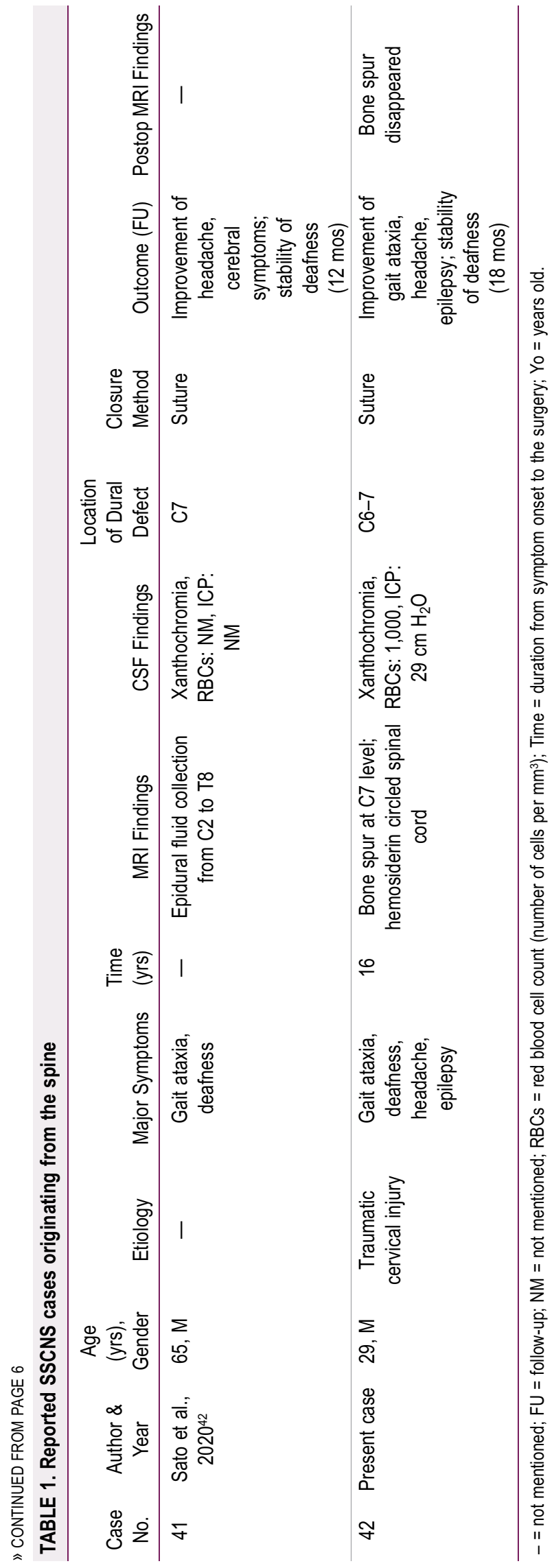

severe headache and vomiting after the drainage tube was pulled out. Lumbar puncture was performed, and test results indicated an extremely high ICP $\left(>33 \mathrm{~cm} \mathrm{H} \mathrm{H}_{2} \mathrm{O}\right)$ on the 15th day after the operation. However, there were no red blood cells in the CSF, and the protein concentration was normal. Although the ventricle was not obviously enlarged, increased ICP was diagnosed, and a lumbar-peritoneal shunt was placed to drain CSF and decrease ICP. The patient recovered uneventfully, and his headache disappeared immediately. His progress was followed up regularly. At the 18-month follow-up visit, the patient was free from headache and seizures, and his ataxia had improved greatly; however, his deafness had not improved.

\section{Discussion \\ Observations}

SSCNS is a rare neurodegenerative disease that results from toxic accumulation of hemosiderin on the surface of the brain and spinal cord. Although the number of reported cases is increasing, the natural history and clinical evolution of SSCNS are poorly understood. Further identification and resolution of the bleeding source do not elicit prompt clinical recovery or radiological reversal of SSCNS in most cases, leading to a major challenge in further diagnosis and treatment. Most clinical signs and symptoms of superficial siderosis are believed to be related to the anatomical distribution of hemosiderin deposits within the neural system. ${ }^{10,11}$ Hemosiderin is apt to deposit in tissues that are exposed to abundant CSF, such as the vermis, superficial sulci and gyri, basal frontal lobe, temporal lobe, brainstem, and spinal cord as well as cranial nerves I, II, and VII, which leads to the typical triad of progressive cerebellar ataxia, central motor disability, and sensorineural hearing loss. Other manifestations have been reported, such as diplopia, hyposmia, amnesia, headache, and seizures. ${ }^{12,13}$ Because most of the damage to the CNS is irreversible, it is vital to determine the etiology and intervene as early as possible. Although extensive diagnostic examinations are used to determine the causative pathologies of bleeding conditions, the etiology of more than $30 \%$ of subarachnoid hemorrhage cases remains unknown. ${ }^{13}$

Recently, attention has been drawn to the association between SSCNS and dural defects in the spinal canal. We searched all related English-language literature in PubMed, GeenMedical, and other databases and identified 41 cases of SSCNS 4,12,14-42 associated with spinal dural defects (Table 1). The cases included 33 male and 8 female patients with an average age of 60.6 years (ranging from 33 to 74 years). The common definite causes were as follows: trauma (11/41), previous surgery (5/41), intervertebral disc herniation (4/41), dural ectasia (2/41), Marfan syndrome (1/41), and dural arteriovenous fistula (1/41). There were 17 cases in which the etiology was not reported. The duration from symptom onset to surgery averaged 6.81 years (ranging from 0.1 to 30 years). The most prevalent clinical manifestations were gait ataxia (31/41) and sensorineural hearing loss (28/41), followed by headache (7/41), tinnitus (6/41), dizziness (5/41), urinary incontinence (6/41), cognitive decline (4/41), limb incoordination (3/41), slurred speech (3/41), dysarthria (3/41), anosmia (2/41), neck pain (2/41), diplopia (1/41), nausea (1/41), emesis (1/41), and blurred vision (1/41). MRI indicated spinal dural defects located in the cervical spine in 5 patients and in the thoracic vertebrae in 23 patients. Most of the CSF examinations showed xanthochromia, increased red blood cells, and intracranial hypotension. Considering that SSCNS was caused by spatially defined lesions with dural defects, 34 patients were treated with reparative surgery. The repair techniques included direct suturing (8 patients), muscle grafts (4 patients), fat grafts ( 6 patients), fibrin glue (9 patients), patches (4 patients), gelatin sponges (3 patients), and artificial dura mater (1 patient). Postoperative MRI in most cases 
showed a reduction or disappearance of epidural effusion. Among the patients with reported results, the prognosis was improved in 10 patients, partially improved in 9 patients, unchanged in 9 patients, and worsened in 3 patients. The improvement rate of headache symptoms was the highest $(100 \%, 7 / 7)$, followed by gait instability symptoms $(19.4 \%, 6 / 31)$; sensorineural hearing loss was not likely to improve $(0 \%$, $0 / 28)$.

In our study, the patient with SSCNS was confirmed to have intermittent subarachnoid hemorrhage caused by a cervical osteophyte that resulted in a dural defect. The repeated activity of the osteophyte led to a small amount of bleeding, which entered the subarachnoid space through the dura defect, causing the deposition of hemosiderin on the surface of the spinal cord and brain and the generation of clinical symptoms. As a result of removal of the bone spurs and repair of the dura mater, subarachnoid hemorrhage was avoided, and the symptoms improved dramatically.

Our patient's epileptic manifestation may be related to the increase in ICP. It has been reported that the causal relationship between intracranial hypertension and epilepsy events is evident clinically and that increased cranial pressure can induce seizures. ${ }^{43}$ Our patient experienced severe headache before epilepsy events, accompanied by increased ICP, which further confirmed the relationship. Our patient also had elevated ICP before dural closure and even higher pressure after dural closure. We speculate that malabsorption of CSF due to dysfunction of the pacchionian granulations caused by recurrent subarachnoid hemorrhage may result in chronic intracranial hypertension. Before dural closure, the dural fistula could drain some of the CSF, which is why the patient's headache was partially relieved when he changed his position. After the dura defect was closed, the extra CSF could not be absorbed and resulted in higher ICP, which was ultimately resolved by shunt surgery.

\section{Lessons}

Our patient represents an extremely rare case of SSCNS with epilepsy originating from traumatic cervical injury. Although this situation is rare, an active search for the cause of subarachnoid hemorrhage, followed by accurate treatment, will ensure a good prognosis for such patients.

\section{References}

1. Fragoso YD, Adoni T, Brooks JBB, et al. Superficial siderosis of the central nervous system is a rare and possibly underdiagnosed disorder. Arq Neuropsiquiatr. 2017;75(2):92-95.

2. Linder S, Nowak DA, Rodiek SO, et al. Secondary intracranial hypertension with acute intracranial pressure crisis in superficial siderosis. J Clin Neurosci. 2008;15(10):1168-1170.

3. Fearnley JM, Stevens JM, Rudge P. Superficial siderosis of the central nervous system. Brain. 1995;118(pt 4):1051-1066.

4. Egawa S, Yoshii T, Sakaki K, et al. Dural closure for the treatment of superficial siderosis. J Neurosurg Spine. 2013;18(4): 388-393.

5. Willeit J, Aichner F, Felber S, et al. Superficial siderosis of the central nervous system: report of three cases and review of the literature. J Neurol Sci. 1992;111(1):20-25.

6. Scheid R, Frisch S, Schroeter ML. Superficial siderosis of the central nervous system: treatment with steroids? J Clin Pharm Ther. 2009;34(5):603-605.

7. Charidimou A, Linn J, Vernooij MW, et al. Cortical superficial siderosis: detection and clinical significance in cerebral amyloid angiopathy and related conditions. Brain. 2015;138(pt 8): 2126-2139.
8. Wang K, Xu Z, Xiong G, Benyan L. Superficial siderosis of the central nervous system manifested with seizures. J Clin Neurosci. 2010;17(2):277-278.

9. Levy M, Turtzo C, Llinas RH. Superficial siderosis: a case report and review of the literature. Nat Clin Pract Neurol. 2007;3(1):54-59.

10. Chen H, Raza HK, Jing J, et al. Superficial siderosis of central nervous system with unknown cause: report of 2 cases and review of the literature. Br J Neurosurg. 2019;33(3):305-308.

11. Stabile A, Di Lazzaro V, Colosimo C, et al. Idiopathic infratentorial superficial siderosis of the central nervous system: case report and review of literature. Neurol Neurochir Pol. 2018;52(1):102-106.

12. Brembilla $C$, Lanterna LA, Bonito V, et al. Updating superficial siderosis of the central nervous system: bleeding of a dorsal osteophyte into the subarachnoid space from a perforating artery. J Neurosurg Spine. 2018;30(1):106-110.

13. Wood VH, Bird PA, Giles EC, Baber WJ. Unsuccessful cochlear implantation in two patients with superficial siderosis of the central nervous system. Otol Neurotol. 2008;29(5):622-625.

14. Kumar N, Lindell EP, Wilden JA, Davis DH. Role of dynamic CT myelography in identifying the etiology of superficial siderosis. Neurology. 2005;65(3):486-488.

15. Kumar N, Cohen-Gadol AA, Wright RA, et al. Superficial siderosis. Neurology. 2006;66(8):1144-1152.

16. Holle D, Sandalcioglu IE, Gizewski ER, et al. Association of superficial siderosis of the central nervous system and low pressure headache. J Neurol. 2008;255(7):1081-1082.

17. Shih $P$, Yang BP, Batjer HH, Liu JC. Surgical management of superficial siderosis. Spine J. 2009;9(8):e16-e19.

18. Kumar N, Lane JI, Piepgras DG. Superficial siderosis: sealing the defect. Neurology. 2009;72(7):671-673.

19. Ikeda T, Noto D, Noguchi-Shinohara M, et al. CSF tau protein is a useful marker for effective treatment of superficial siderosis of the central nervous system: two case reports. Clin Neurol Neurosurg. 2010;112(1):62-64.

20. Kumar N, Miller GM, Piepgras DG, Mokri B. A unifying hypothesis for a patient with superficial siderosis, low-pressure headache, intraspinal cyst, back pain, and prominent vascularity. J Neurosurg. 2010;113(1):97-101.

21. Cheng CY, Chen MH, Wang SJ, Lin KP. A proposed mechanism of superficial siderosis supported by surgical and neuroimaging findings. Med Hypotheses. 2011;76(6):823-826.

22. Boncoraglio GB, Ballabio $E$, Erbetta $A$, et al. Superficial siderosis due to dural defect with thoracic spinal cord herniation. J Neurol Sci. 2012;312(1-2):170-172.

23. Yokosuka J, Takai K, Komori T, Taniguchi M. Superficial siderosis: bleeding from the bone marrow after laminectomy for spinal tumor removal. J Neurosurg Spine. 2014;21(6):905-908.

24. Schievink WI, Wasserstein $P$, Maya MM. Intraspinal hemorrhage in spontaneous intracranial hypotension: link to superficial siderosis? Report of 2 cases. J Neurosurg Spine. 2016;24(3):454-456.

25. O'Hare M, Fearon C, Kavanagh EC, et al. Superficial siderosis and dural ectasia: a case report. Neurology. 2016;87(16):1743-1744.

26. Ryu SM, Kim ES, Kim SK, et al. Superficial siderosis of the central nervous system originating from the thoracic spine: a case report. Korean J Spine. 2016;13(2):83-86.

27. Madkouri R, Grelat M. Teaching Neurolmages: superficial siderosis due to a dural cervical arteriovenous fistula. Neurology. 2017;88(8):e66.

28. Sakoda A, Yamashita KI, Hayashida M, et al. A case of superficial siderosis ameliorated after closure of dural deficit detected by MRICISS (constructive interference in steady state) imaging. Rinsho Shinkeigaku. 2017;57(4):180-183.

29. Takai K, Komori T, Niimura M, Taniguchi M. Superficial siderosis of the central nervous system associated with intraspinal hemorrhage from ventral thoracic epidural veins and a ventral spinal CSF leak: case report. J Neurosurg Spine. 2017;26(6):751-753. 
30. Hiraka T, Kanoto M, Toyoguchi $Y$, et al. Superficial siderosis associated with a spinal dural defect. Magn Reson Med Sci. 2018; 17(3):189-190.

31. Bower M, Farag M, Phielipp N. Superficial siderosis and dural ectasia in a patient with Marfan syndrome. Clin Neuroradiol. 2018; 28(4):605-607.

32. Hosokawa M, Murata KY, Hironishi M, et al. Superficial siderosis associated with duplicated dura mater detected by CISS reverse MRI. J Neurol Sci. 2018;392:38-43.

33. Arishima H, Higashino Y, Yamada S, et al. Spinal endoscopy combined with selective CT myelography for dural closure of the spinal dural defect with superficial siderosis: technical note. J Neurosurg Spine. 2018;28(1):96-102.

34. Camlar M, Karadag A, Oztekin O, Ozer F. Superficial siderosis of the central nervous system due to recurrent surgeries of the thoracic spine: a rare case. World Neurosurg. 2018;119: 384-388.

35. Nasri A, Kacem I, Sidhom Y, et al. Isolated spinal cord compression syndrome revealing delayed extensive superficial siderosis of the central nervous system secondary to cervical root avulsion. J Spinal Cord Med. 2018;41(4):490-495.

36. Machino M, Imagama S, Ishiguro N. Detection of spinal dural defect in superficial siderosis by intraoperative ultrasonography. World Neurosurg. 2019;129:386-388.

37. Vellutini EAS, Stamm AEC, Martins HO, et al. Role of transnasal endoscopic surgery in the treatment of superficial siderosis of central nervous system secondary to clivus arachnoidocele: report of successful case and literature review. World Neurosurg. 2019;126:142-145.

38. Nathoo N, Naik S, Rempel J, et al. Superficial siderosis treated with dural tear repair and deferiprone. Pract Neurol. 2021;21:71-72. doi:10.1136/practneurol-2020-002657

39. Katoh H, Shibukawa S, Yamaguchi K, et al. A combination of magnetic resonance imaging techniques to localize the dural defect in a case of superficial siderosis. A case report. Medicines (Basel). 2020;7(6):36. doi:10.3390/medicines7060036

40. Wiącek M, Perenc A, Tołpa B, Bartosik-Psujek H. Superficial siderosis and intracranial hypotension syndrome following brachial plexus avulsion injury. A case of surgical treatment. Clin Neurol Neurosurg. 2020;192:105723.

41. Cornips E, Grouls M, Bekelaar K. Transdural thoracic disk herniation with longitudinal slitlike dural defect causing intracranial hypotension: report of 2 cases. World Neurosurg. 2020;140: e311-e319.

42. Sato $Y, E n d o T$, Inoue T, et al. Successful endoscopic identification of the bleeding source in the ventral dura of the cervical spine in a case of superficial siderosis. J Neurosurg Spine. 2020;33(1): 73-76.

43. Ohira M, Takao M. Superficial siderosis. Article in Japanese. Brain Nerve. 2018;70(10):1107-1113.

\section{Disclosures}

The authors report no conflict of interest concerning the materials or methods used in this study or the findings specified in this paper.

\section{Author Contributions}

Conception and design: Duan. Acquisition of data: Yuan, Shen. Analysis and interpretation of data: Yuan, Wang. Drafting the article: Xu. Critically revising the article: Duan. Approved the final version of the manuscript on behalf of all authors: Duan.

\section{Correspondence}

Hongzhou Duan: Peking University First Hospital, Beijing, China. duanhongzhou@126.com. 